\title{
Treatment of rising damp in historical buildings: wall base ventilation
}

\author{
M. Isabel M. Torres ${ }^{\mathrm{a}, *}$, Vasco Peixoto de Freitas ${ }^{\mathrm{b}}$ \\ ${ }^{a}$ Civil Engineering Department, Faculty of Science and Technology of Coimbra University, Pólo II-Pinhal de Marrocos-3030-290 Coimbra, Portugal \\ ${ }^{\mathrm{b}}$ Building Physics Laboratory (LFC)-Civil Engineering Department, Faculty of Engineering of Porto University (FEUP), Rua Dr. Roberto Frias, \\ 4200-465 Porto, Portugal
}

Received 7 June 2005; received in revised form 7 July 2005; accepted 29 July 2005

\begin{abstract}
Intervention in older buildings increasingly requires extensive and objective knowledge of what one will be working with. The multifaceted aspect of work carried out on buildings tends to encompass a growing number of specialities, with marked emphasis on learning the causes of many of the problems that affect these buildings and the possible treatments that can solve them. Moisture transfer in walls of old buildings, which are in direct contact with the ground, leads to a migration of soluble salts responsible for many building pathologies.

We feel that many of the techniques currently used to minimise rising damp are not effective, in particular when dealing with walls of considerable thickness and heterogeneous materials.

This paper will present the results of a project developed at the Building Physics Laboratory (LFC) at the Faculty of Engineering of Porto University. The project focussed on performing experiments to validate a new technology for treating rising damp in walls of historical buildings: wall base ventilation. We will also present some of the results obtained in the numerical simulations carried out [Torres MI, Freitas VP. Rising damp in historical buildings. Research in building physics - Proceedings of the Second International Conference on Building Physics, Leuven, Belgium; 2003. p. 369-75; Torres MIM. Rising damp in historical building walls. Ph.D. thesis, Coimbra, FCTUC, 2004 [in Portuguese].].
\end{abstract}

(C) 2005 Elsevier Ltd. All rights reserved.

Keywords: Rising damp; Wall; Historical buildings; Hygrothermal properties; Wall base ventilation

\section{Introduction}

Intervention in older buildings increasingly requires extensive and objective knowledge of what one will be working with. The multifaceted aspect of work carried out on buildings tends to encompass a growing number of specialities, with marked emphasis on learning the causes of many of the problems affecting these buildings and the possible treatments to solve them.

Although many historical buildings in Portugal have undergone refurbishment to erase, or at least to minimise, the effect of rising damp, the results have not been satisfactory.

\footnotetext{
${ }^{*}$ Corresponding author.
}

In the Building Physics Laboratory (LFC) of the Faculty of Engineering - Porto University (FEUP) we have been performing experimental investigation to validate the efficiency of a technique for treating rising damp in walls of older buildings. The technique consists of ventilating the base of walls through a natural ventilation process or by installing a hygro-regulated mechanical ventilation device.

\section{Treatment techniques against rising damp}

\subsection{General}

Any of the following techniques can be used to treat walls with rising damp [1,2]: 
- By creating a physical or chemical barrier.

- By creating a potential against the capillary potential.

- By applying atmospheric drainage.

- By applying a coating with controlled porosity.

- By concealing the anomalies.

- By ventilating the wall base.

\subsection{Creating a physical or chemical barrier}

The main objective of this technique is to create a physical or chemical barrier at the base of the affected walls to prevent rising damp. We can reduce the absorbent area, place watertight barriers or apply hydrofuge products.

\subsubsection{Reducing the absorbent section}

This technique consists basically of diminishing the absorbent area by replacing part of the porous material (wall) by air pockets, thereby not only reducing the amount of water absorbed but also increasing evaporation.

\subsubsection{Placing watertight barriers}

A watertight material (bitumen, polymer-based mortar, corrugated sheets of stainless steel or lead sheets) is inserted into the wall's buried section to prevent water from migrating to upper levels.

\subsubsection{Applying hydrofuge products}

Whereas the above-mentioned techniques of creating a damp-proof cut-off consist of a physical barrier, this technique introduces a chemical barrier. The chemicals can be introduced into the walls by diffusion or injection through holes drilled into the walls at intervals to ensure that the chemical barrier covers the entire width and length of the affected walls.

\subsection{Creating a potential against the capillary potential}

This is an old technique that delays rising of the water by creating an electric potential against the capillary potential. This technique is no longer popular because it is not considered to be effective.

\subsection{Applying atmospheric drainage}

The principle behind atmospheric drainage siphons is the fact that damp air is heavier than dry air. Knappen [1] believed that inserting oblique drainage tubes into walls would release damp air (coming from inside the wall), thereby facilitating the wall-drying process.

\subsection{Applying a coating with controlled porosity}

Applying outer coatings that promote the evaporation of humidity from inside the walls and that impede salt from crystallising on the outside is a technique that conceals the problem.

\subsection{Concealing anomalies}

When the causes of rising damp cannot be eliminated, we can decide to put up a new wall separated from the original wall with a ventilation space, which is a type of damp-proof course system concealing the anomalies.

\subsection{Ventilating the wall base}

Creating ventilated peripheral channels, in addition to diminishing water contact with porous walls, increases the evaporation of absorbed water. This evaporation takes place below the ground level. Installing a hygroregulated mechanical ventilation device can increase this system's effectiveness.

\subsection{Comparative analysis of the different treatment techniques}

All the aforementioned techniques for treating rising damp have advantages and disadvantages. Creating a damp-proof course system by reducing the absorbent area is an interesting idea but is not used often for aesthetic and structural reasons. Creating watertight barriers causes vibration that can bring about stability problems. Introducing hydrofuge products has little effect when dealing with very thick and very heterogeneous walls, as is usually the case in historical buildings.

Creating electric potential and installing atmospheric drainage siphons are techniques that are considered ineffective.

The main drawback of applying coatings with controlled porosity and porometry is that this technique cannot be used on walls without renderings (and most of our historical buildings do not have rendering). Concealing anomalies behind a wall built with a ventilation space separating it from the original wall would undoubtedly be effective if done correctly. Nevertheless, in addition to reducing space, concealing original walls may not be viable for historical buildings.

The conclusion is that none of the techniques described is particularly adequate for treating rising damp in historical buildings. We therefore carried out experimental and numerical research at the LFC to analyse the effectiveness of wall base ventilation as a means of solving the problem of rising damp. 


\section{Experimental study}

\subsection{Physical model}

The selected physical model consists of a prismatic system measuring $1.58 \times 2.00 \times 0.20 \mathrm{~m}^{3}$, waterproofed on the two top sides to prevent moisture in this direction, with walls made of limestone slabs measuring $30 \times 20 \times 200 \mathrm{~cm}^{3}$, with $1 \mathrm{~cm}$ thick lime mortar joints (Fig. 1).

We built reservoirs of approximately $2.20 \times$ $2.50 \times 0.50 \mathrm{~m}^{3}$, using cement blocks that had been waterproofed on the inside. We built stone walls inside each vat according to the physical model described above (Fig. 2). The initial conditions of the walls were: $65 \% \mathrm{RH}$ and $25^{\circ} \mathrm{C}$.

These experiments were meant to characterise how these walls were affected by rising damp in view of different boundary conditions. They also validated the calculation model, with the ultimate aim of characterising the performance of new techniques of treating rising damp in walls of historical buildings. The tested configurations are shown in Table 1 and Fig. 3 [2,3].

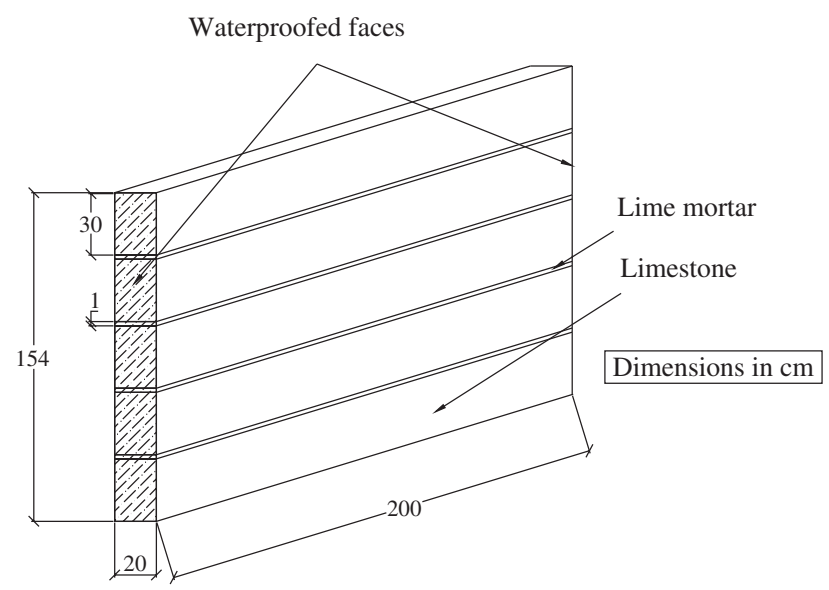

Fig. 1. Physical model.
To evaluate moisture transfer inside the walls, we inserted probes at different heights and different depths to measure the relative humidity and temperature. These probes were then connected to a data acquisition and recording system. We left one of the probes out of the walls so that we could measure the climate $(\mathrm{RH}$ and temperature) in the Laboratory during the tests. Next we present the average values of the relative humidity and temperature measured during the five tests.

\subsection{Presentation of the results}

\subsubsection{Configurations 1 and 5}

We will begin by presenting the results obtained for configurations 1 and 5 . The only difference was that one side of the wall in configuration 5 was completely covered with tile. With these two boundary conditions we intended to analyse the influence of using waterproof materials (such as tiles).

Temperature and relative humidity variations inside the wall were recorded every hour. Fig. 4 shows the change in the relative humidity in the first two stone layers and in the second joint for both configurations.

From the results we can observe the following:

- The probe in the first stone layer, at $5 \mathrm{~cm}$ from the side of the wall covered with tile, registered $100 \%$ relative humidity after $8 \mathrm{~h}$, whereas the other probes took $55 \mathrm{~h}$ to reach this reading. This difference is explained by the fact that rising damp increases when drying conditions are hampered by using more waterproof coatings. By covering the entire wall with tile, we practically eliminated any evaporation through that side of the wall. This is why the probes on the tiled side indicated a much faster rise in the relative humidity than the others. This phenomenon occurred in all the other joints and in all the other stone layers.

- In configuration 1 the rising damp stabilised when it reached the 2 nd joint, in about $1400 \mathrm{~h}$. In

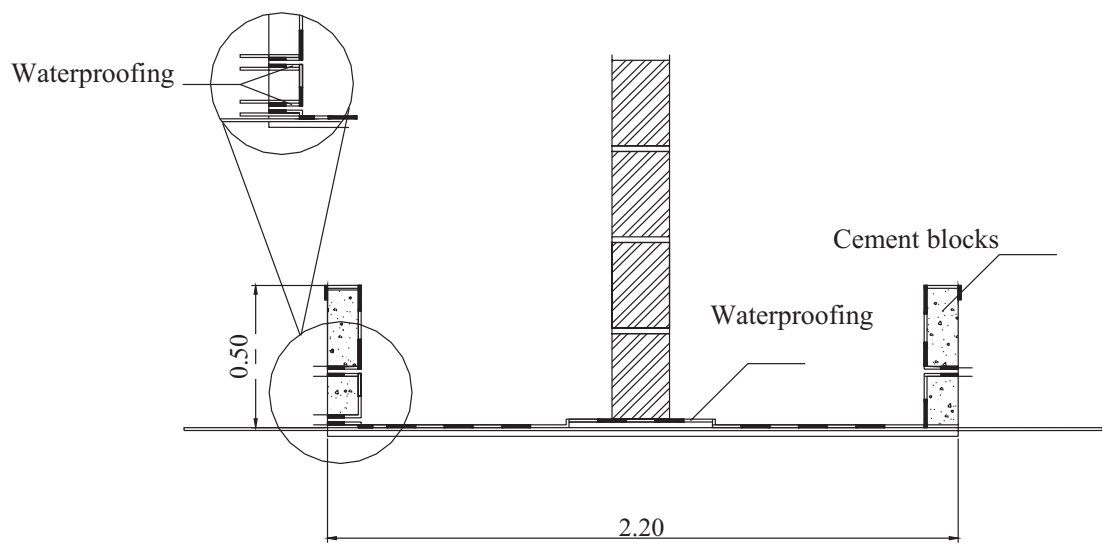

Fig. 2. Configuration of the reservoirs. 
Table 1

Average values of RH and temperature

\begin{tabular}{llllll}
\hline & Configuration 1 & Configuration 2 & Configuration 3 & Configuration 4 & Configuration 5 \\
\hline Relative humidity & $53 \%$ & $58 \%$ & $59 \%$ & $66 \%$ & $75 \%$ \\
Temperature & $22{ }^{\circ} \mathrm{C}$ & $22{ }^{\circ} \mathrm{C}$ & $20{ }^{\circ} \mathrm{C}$ & $15 \%$ & $14{ }^{\circ} \mathrm{C}$ \\
\hline
\end{tabular}

\begin{tabular}{|l|}
\hline \\
\hline Configuration 5
\end{tabular}

Fig. 3. Different boundary conditions.

configuration 5 , however, the probes in the 2 nd joint showed $100 \%$ relative humidity after $800 \mathrm{~h}$, and after $1500 \mathrm{~h}$ all the probes in the third stone layer had registered $100 \%$ relative humidity.

\subsubsection{Configurations 3 and 4}

In configurations 3 and 4 we measured the behaviour of a wall with both sides underground by placing sand on both sides of the wall up to a height of $45 \mathrm{~cm}$ above its base. The sand was saturated $(100 \% \mathrm{RH})$ during the tests.

In configuration 4, since we wished to assess the effect of placing a ventilation system at the base of the wall, we placed a ventilation box on both sides of the wall (Fig. 5). We left two openings to which we attached flexible tubes to ventilate the box. We attached a mechanical extractor at one opening and left the other one free to allow air to enter freely (Fig. 6). This extraction system was left running for the duration of the test so that we could ensure that the temperature and relative humidity inside the box were identical to the conditions we had in the laboratory.

Fig. 7 shows the results obtained in these two tests in which the different probes recorded the relative humidity.

We also can see the change in relative humidity in the cross-sections located $16.5 \mathrm{~cm}$ and $61.5 \mathrm{~cm}$ (Fig. 8) above the wall base, as is illustrated in Figs. 9 and 10 . As the profile is fully symmetrical there were only two measuring probes at each level.

The following main observations were drawn from the experimental research:

- Placing a ventilation system at the wall base is a good technique for reducing the level of rising damp.

- After $50 \mathrm{~h}$, the first stone layer in configuration 3 was already completely saturated, and the same occurred in configuration 4 after $65 \mathrm{~h}$. 


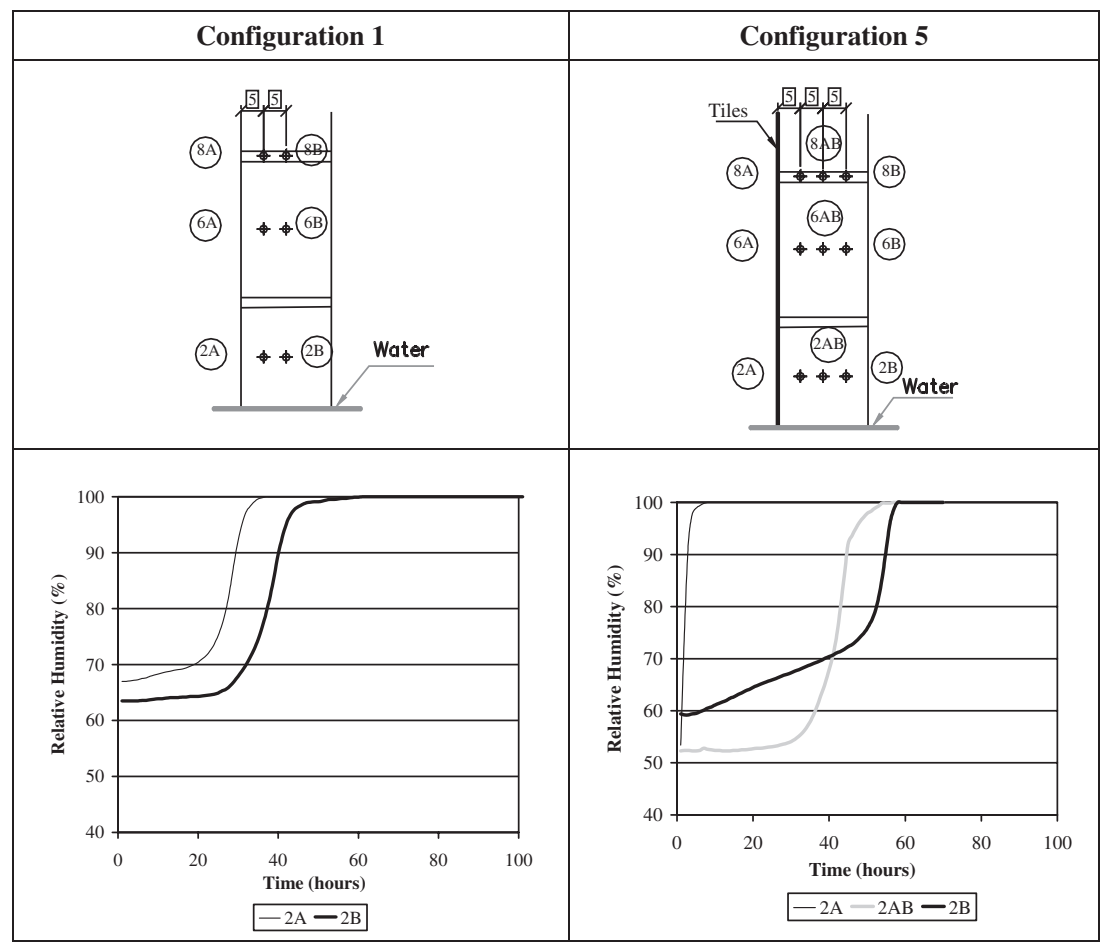

(a)

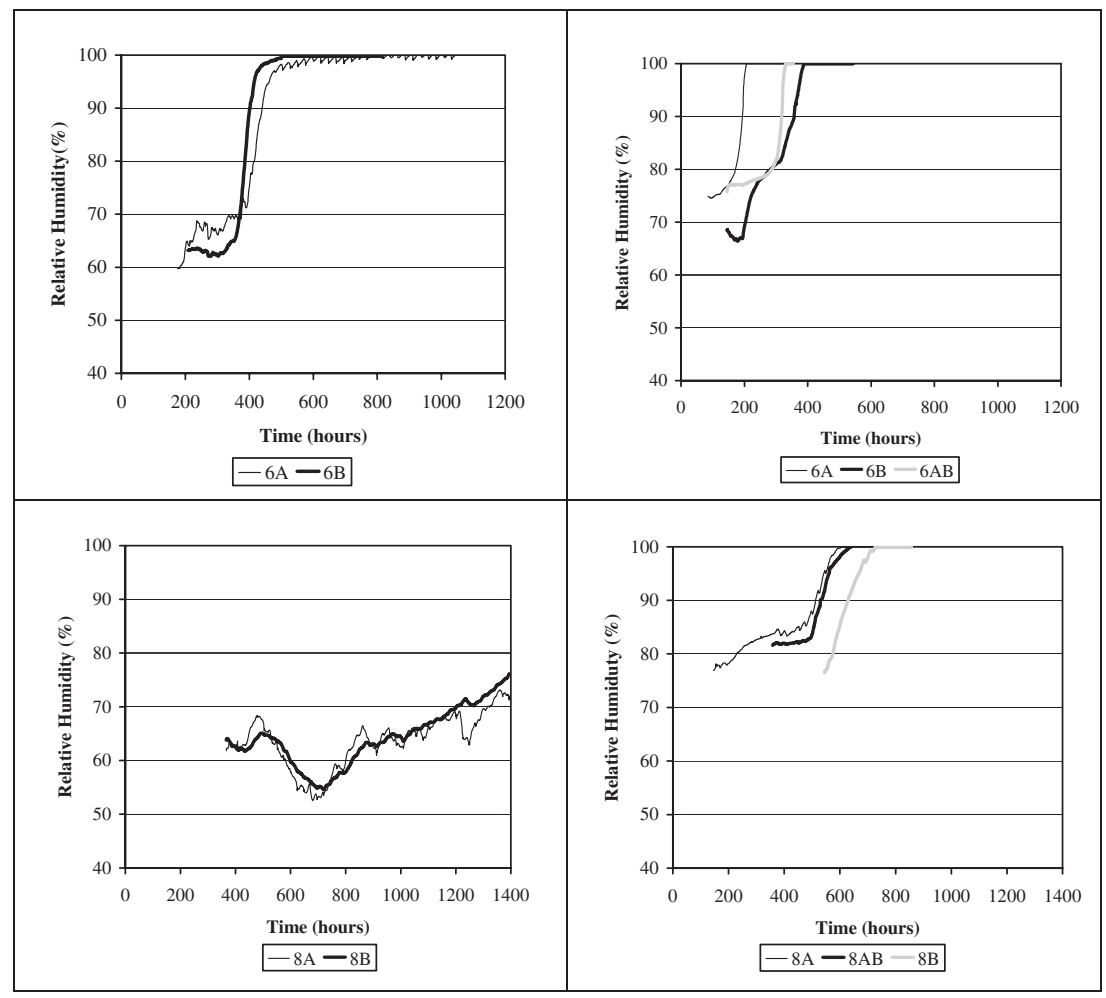

(b)

Fig. 4. (a) Results for configurations 1 and 5. (b) Results for configurations 1 and 5.

- The differences become more noticeable the higher up the wall we go. After approximately $350 \mathrm{~h}$, the moisture front had already reached the second stone layer in configuration 3, whereas in configuration 4 it took $1000 \mathrm{~h}$ for this to occur. 
- Even after approximately $1400 \mathrm{~h}$ of testing, none of the probes in the third stone layer in configuration 4 registered $100 \%$ relative humidity. In contrast, in configuration 3 , after approximately $1000 \mathrm{~h}$, some of the probes placed in the third stone layer registered $100 \%$ relative humidity. These results can be explained by the fact that the ventilation in the base of the walls (configuration 4) limits the level reached by the moisture front (Fig. 10).

\section{Numerical simulation}

\subsection{Simulation program used and validation}

The automatic calculation programs to evaluate changes in the moisture content and temperature inside walls are essential instruments in simulating the wall's behaviour in the presence of humidity, depending on the internal and external climactic conditions [4-6].

The WUFI-2D calculation program was used in the numerical simulations. This program is based on the

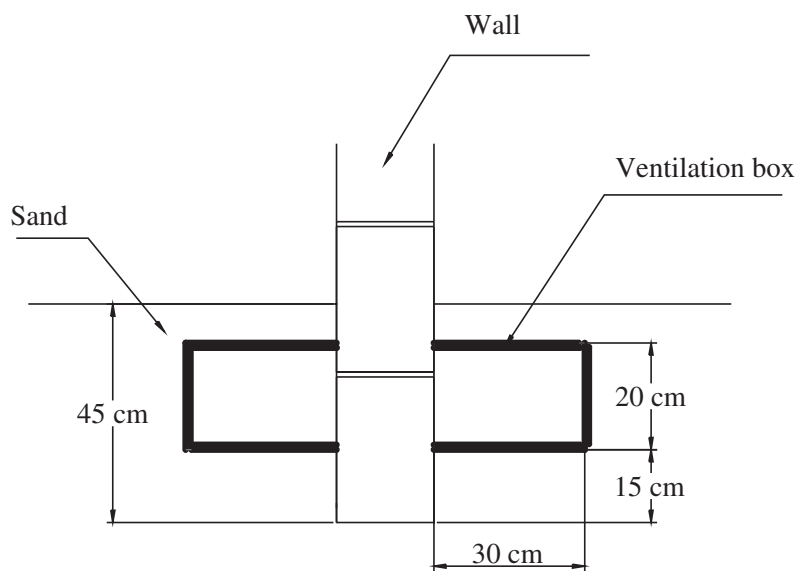

Fig. 5. Ventilation box.
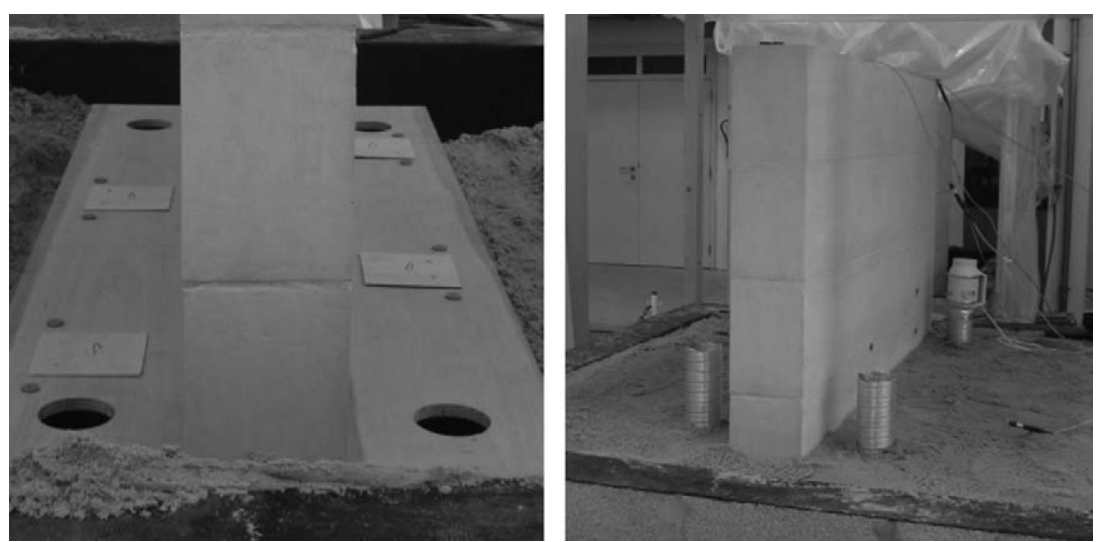

Fig. 6. Ventilation box with flexible tubes and mechanical extractors.

$\phi[-]$ following heat and moisture transfer [7-9]:

$\frac{\mathrm{d} H}{\mathrm{~d} T} \frac{\partial T}{\partial t}=\nabla(\lambda \nabla T)+h_{\mathrm{v}} \nabla\left(\delta_{\mathrm{p}} \nabla\left(\phi p_{\text {sat }}\right)\right)$,
$\frac{\mathrm{d} w}{\mathrm{~d} \phi} \frac{\partial \phi}{\partial t}=\nabla\left(D_{\phi} \nabla \phi+\delta_{\mathrm{p}} \nabla\left(\phi p_{\text {sat }}\right)\right)$,

where

$\mathrm{d} H / \mathrm{d} T\left(\mathrm{~J} / \mathrm{m}^{3} \mathrm{~K}\right)$ heat storage capacity of the moist building material,

$\mathrm{d} w / \mathrm{d} \phi\left(\mathrm{kg} / \mathrm{m}^{3}\right) \quad$ moisture storage capacity of the building material,

$\lambda(\mathrm{W} / \mathrm{m} \mathrm{K})$

$D_{\phi}(\mathrm{kg} / \mathrm{ms})$

$\delta_{\mathrm{p}}(\mathrm{kg} / \mathrm{m} \mathrm{s} \mathrm{Pa})$

$h_{\mathrm{v}}(\mathrm{J} / \mathrm{kg})$

$p_{\text {sat }}(\mathrm{Pa})$

$T\left({ }^{\circ} \mathrm{C}\right)$ thermal conductivity of the moist building material, liquid conduction coefficient of the building material, water vapour permeability of the building material, evaporation enthalpy of the water, water vapour saturation pressure, temperature, relative humidity.

Of all the variables that can be obtained through numerical calculations, we chose those that could be recorded in our experiments: temperature and relative humidity. Since the experiments took place under isothermal conditions, only the change in relative humidity is important.

\subsection{Material properties}

Use of the numerical simulation program requires knowledge of the boundary conditions and of the materials' hygrothermal properties. Table 2 shows the properties of the respective materials: limestone and mortar.

All properties (except specific heat) were experimentally determined in the LFC at FEUP, in accordance with the respective European Standard [10-13]. 


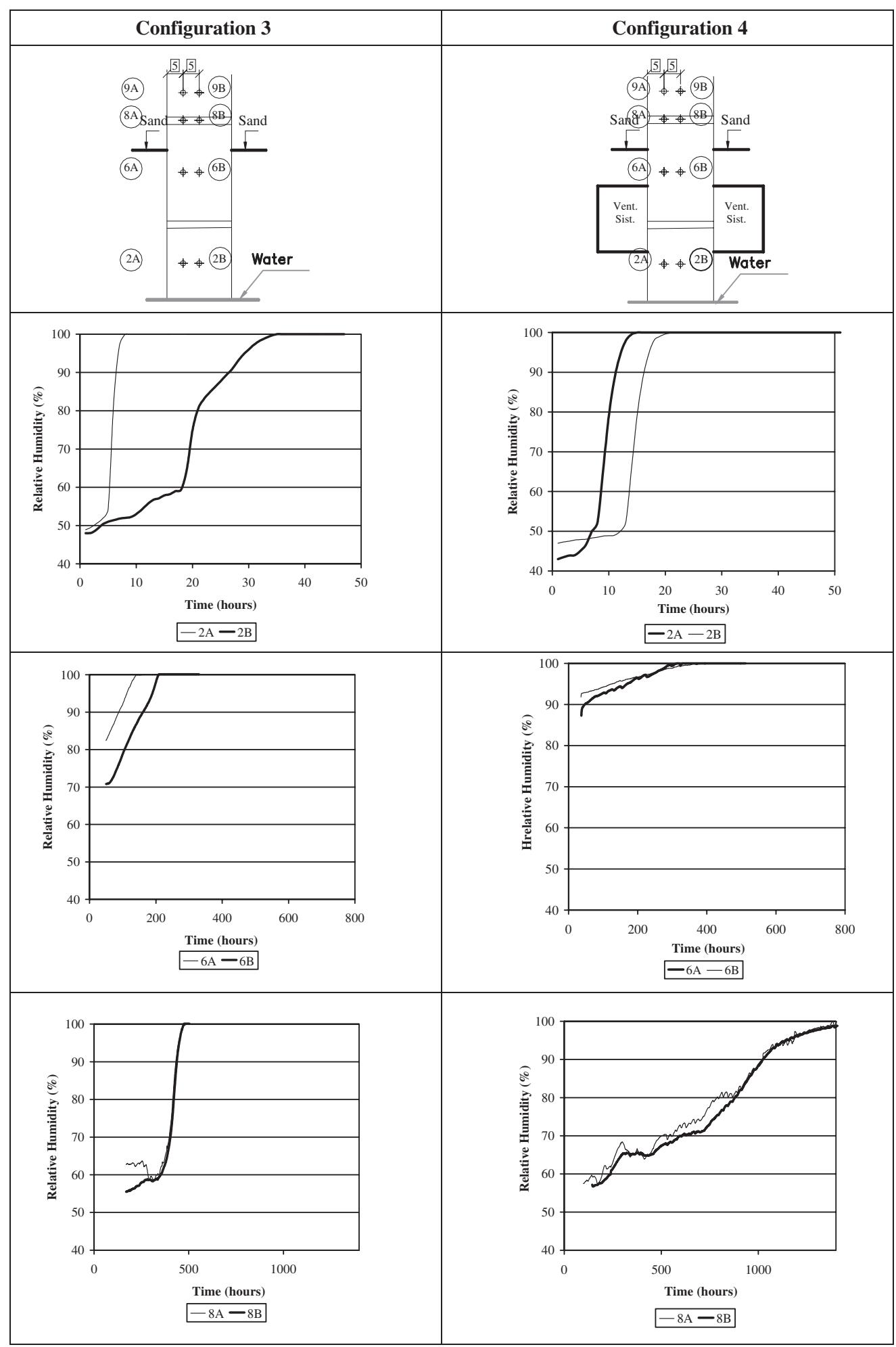

(a)

Fig. 7. (a) Results for configurations 3 and 4. (b) Results for configurations 3 and 4 (cont.).

\subsection{Simulation results}

For each simulation we introduced the properties of the materials, the specific boundary conditions for each situation, the values measured for $\mathrm{RH}$ and the air temperature in the laboratory, and the actual duration of each test (which differed according to the configuration). In configuration 4 we simulated the ventilation 


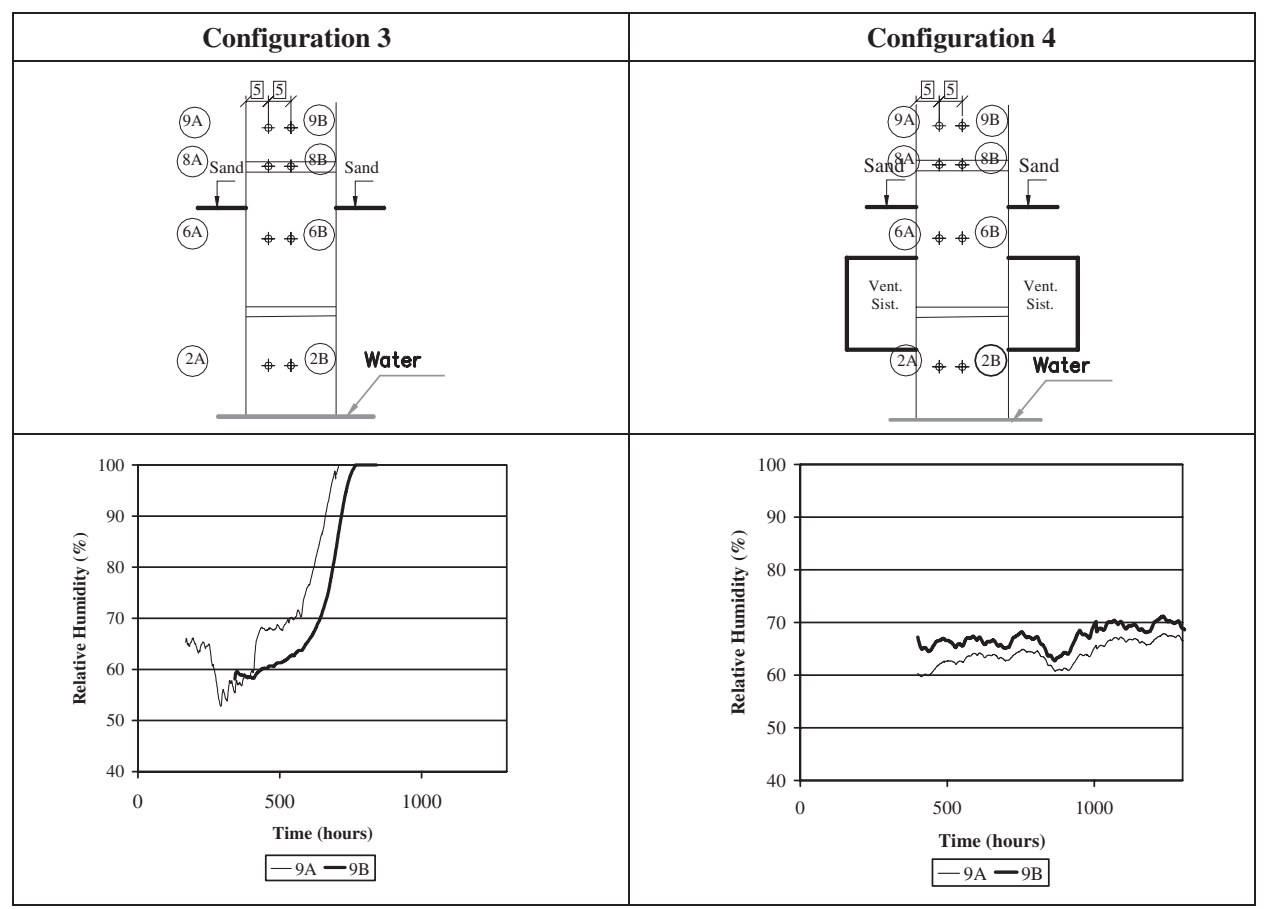

(b)

Fig. 7. (Continued)

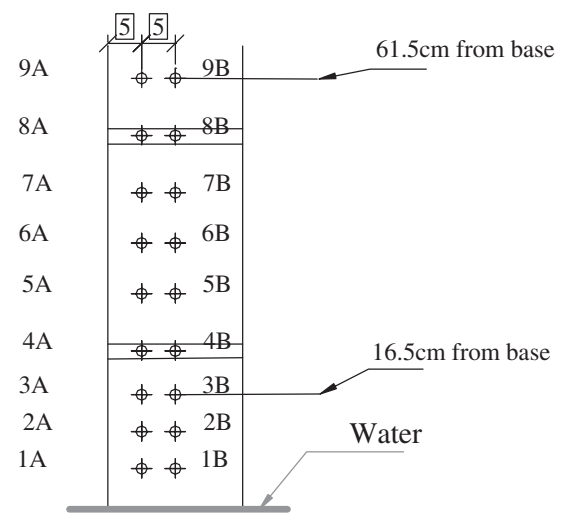

Fig. 8. Position of the probes in the transversal section.

box by imposing the same $\mathrm{RH}$ and temperature conditions on the box as the laboratory air.

\subsubsection{Configuration 1 and 5}

The numerical simulation results show that in the first stone layer the differences observed (between the experiment and the simulation) are not significant (in the simulation the rising damp advanced slightly slower). However, in the first joint and in the second stone layer the differences between simulation and experiment are considerable $[2,3]$.

Fig. 11 shows the simulation results for configurations 1 and 5.

\subsubsection{Configurations 3 and 4}

Once again, the major differences between the numerical simulations and experimentation become noticeable after the second stone layer and always showed less and slower capillary ascent.

\subsection{Analysis of the simulation results}

An interpretation of the numerical simulation results allows us to state the following:

- When we hamper evaporation by placing tiles on one side of the wall and increase the relative humidity to $100 \%$, the level of rising damp increases.

- Faster rising damp is always observed on the wall side where evaporation conditions have been hampered.

- When we compare the simulations for configurations 3 and 4, where the only difference is forced ventilation at the base of the walls (whereby relative humidity conditions inside the wall base ventilation box become equal to external conditions), we can see that in configuration 4 the rising damp was slower and, basically, reached lower levels. This fact became more evident when comparing simulations of 1-year periods (Fig. 12).

We can therefore conclude that the relative behaviour of the different configurations, as simulated using the calculation program, was identical to the relative 
Configuration 3

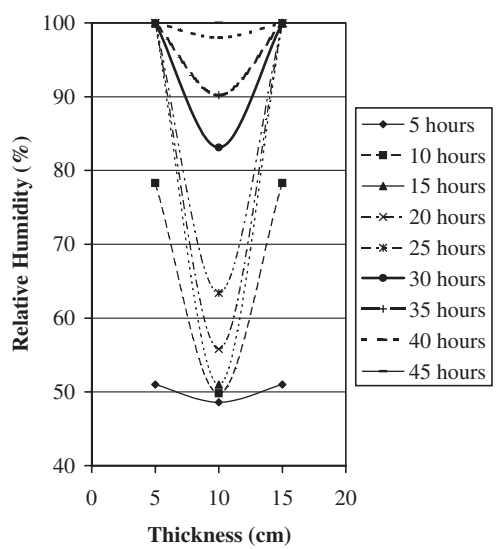

Configuration 4

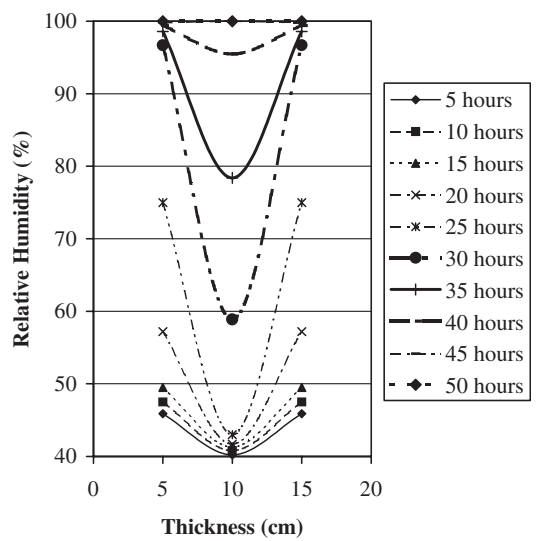

Fig. 9. Relative humidity variation in a section at $16.5 \mathrm{~cm}$ from the base.
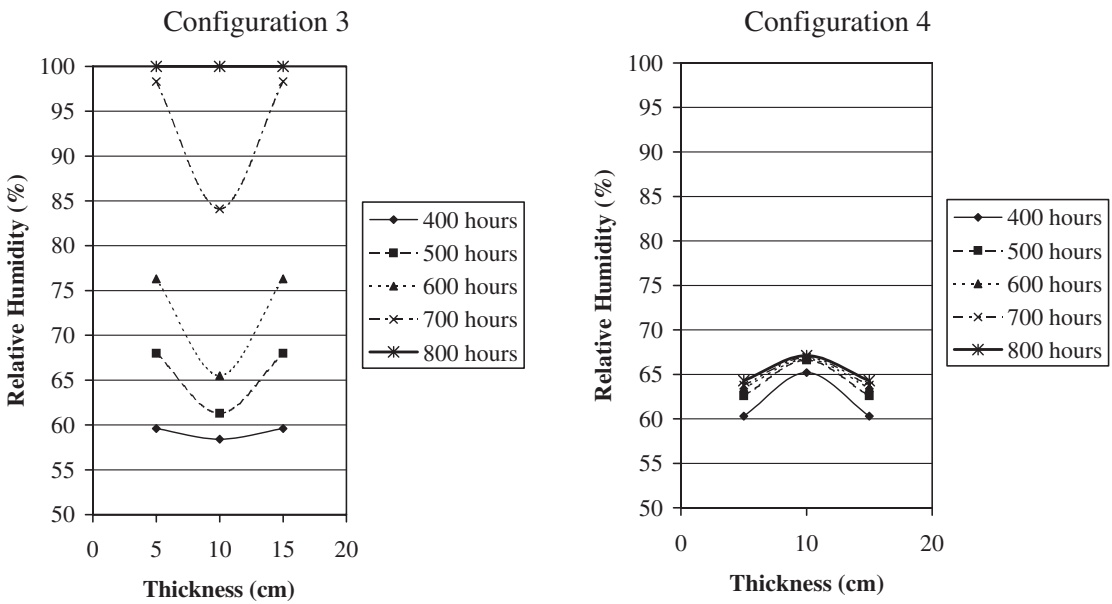

Fig. 10. Relative humidity variation in a section at $61.5 \mathrm{~cm}$ from the base.

behaviour of the respective experimental configurations, therefore validating the calculation program from a qualitative standpoint.

However, when we compared the test results with the respective simulations, we noticed the following differences:

- No significant differences were observed regarding how the first layers of all stone configurations were affected.

- As we advance up the walls, the differences become more pronounced and the advancement of the humid front in the simulations is always slower than the advancement observed in the experiments, which indicates that the problem may possibly lie in the interfaces between layers.

- For building walls consisting of multiple layers, research on the transfer of damp requires knowledge of the conditions of continuity, which may include: hydraulic continuity, full contact or air pockets between layers. The interface between layers deter- mines the kinetics of absorption and drying of the building's components. When there is full contact between the materials (without continuity of the porous structure), there is no continuity of the capillary pressure and there is maximum transmitted flow function of the interface's hydric resistance which conditions the transfer. The interface between layers slows down the process of wetting in a way which becomes more noticeable as the maximum transmitted flow decreases. This flow translates the hydric resistance between layers. We believe that the differences observed are caused by the influence of interfaces between the mortar and the stone $[14,15]$.

\section{Conclusions}

This research led to the following main conclusions:

- In historical buildings, the traditional techniques of treating rising damp are not effective, and wall 
Table 2

Material properties

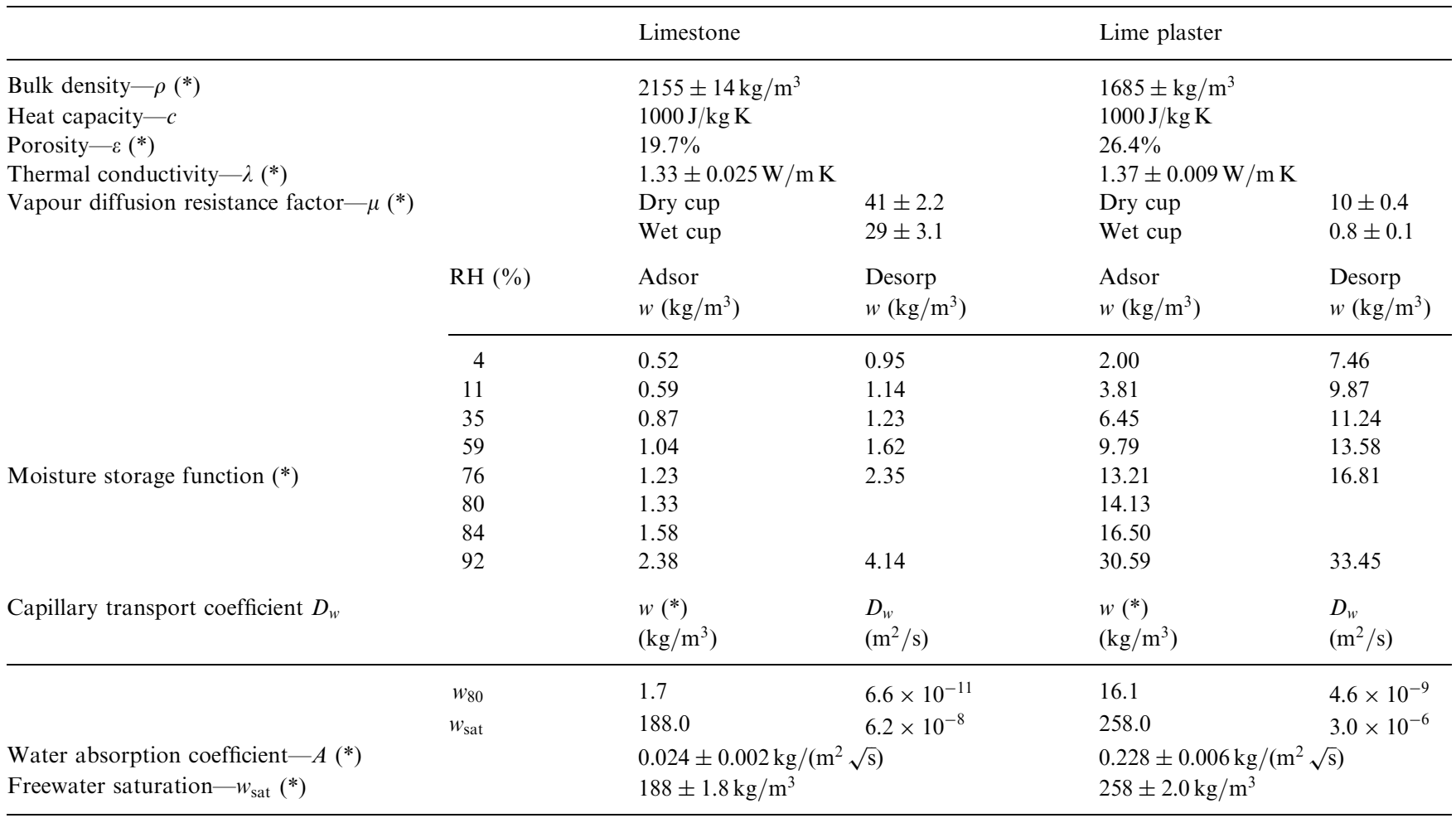

$\left.{ }^{*}\right)$ Experimental determination.

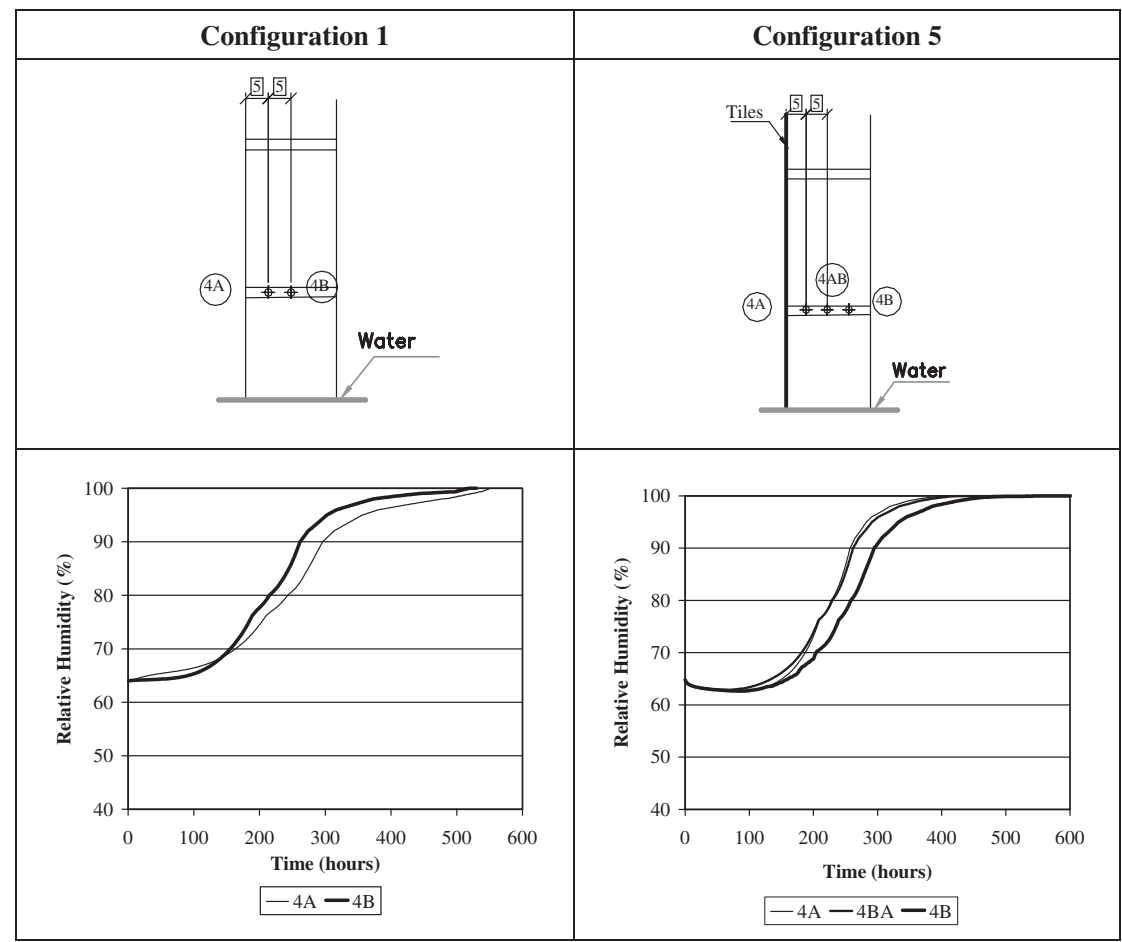

Fig. 11. Results for simulations of configurations 1 and 5. 


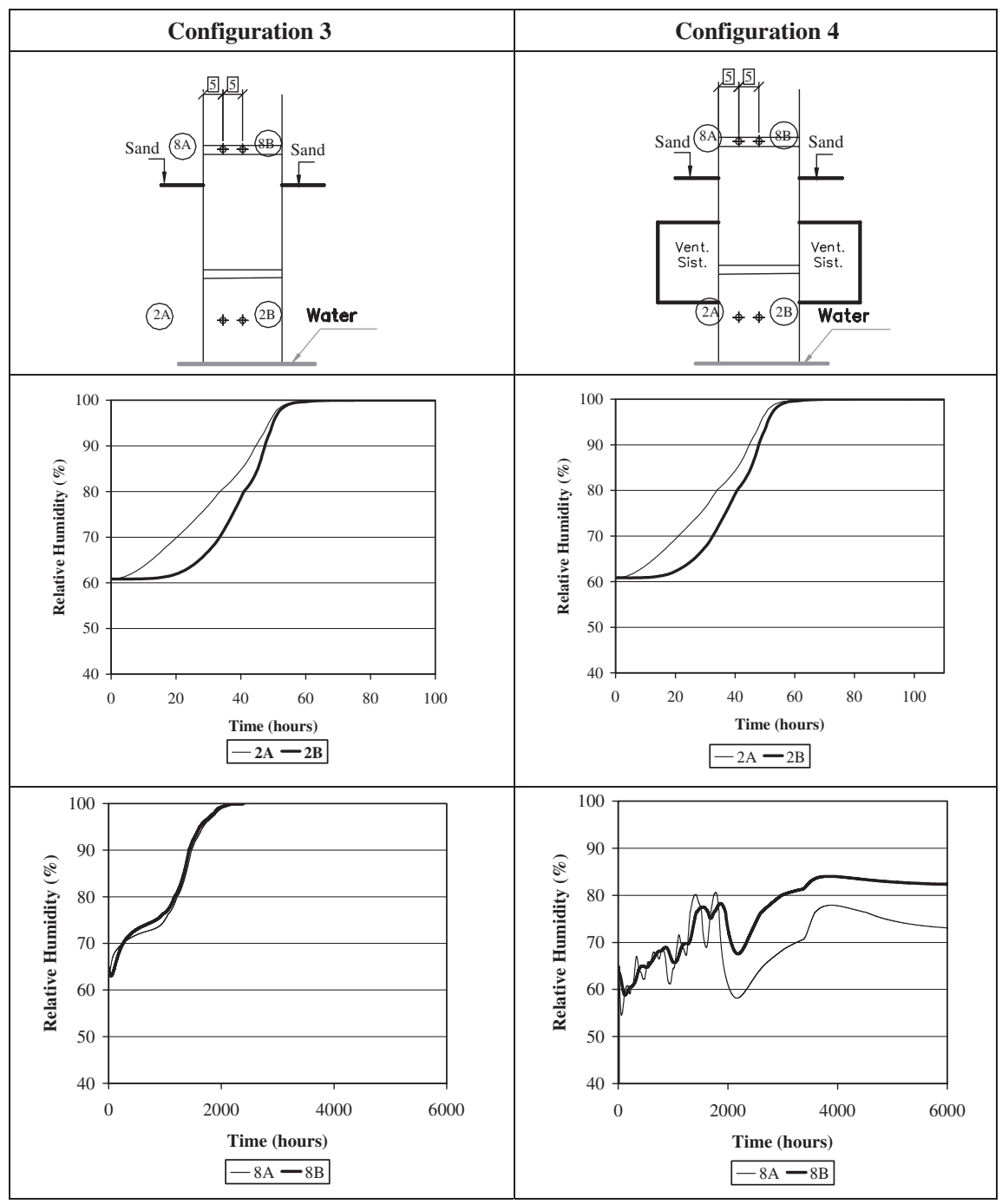

Fig. 12. Results for simulations of configurations 3 and 4.

ventilation is a simple technology that holds great potential.

- The experimental results show that implementing this new treatment technology (wall base ventilation) reduced the level of rising damp.

- The numerical simulation results in the first layer are similar to those obtained experimentally, which provide qualitative validation of the calculation program.

\section{References}

[1] CSTC-Les procèdes de traitement des maçonneries contre l'humidité ascensionnelle. Note d'information technique 162, Bruxelles; Nov-Dec 1985.

[2] Torres MIM. Rising damp in historical building walls. Ph.D. thesis, Coimbra, FCTUC, 2004 [in Portuguese].
[3] Torres MI, Freitas VP. Rising damp in historical buildings. Research in building physics - Proceedings of the Second International Conference on Building Physics. Leuven, Belgium; 2003. p. 369-75.

[4] Bomberg M. Moisture flow through porous building materials. Report no. 52, Division of Building Technology, Lund Institute of Technology, Sweden; 1974.

[5] De Vries D. The theory of heat and moisture transfer in porous media revisited. Journal of Heat and Mass Transfer 1987;30(7): $1343-50$.

[6] Luikov AV. Systems of differential equations of heat and mass transfer in capillary - porous bodies. Journal of Heat and Mass Transfer 1975;18(1-A):1-14.

[7] Holm A, Kunzel HM. Two-dimensional transient heat and moisture simulations of rising damp with WUFI-2D. Proceedings of the Second International Conference on Building Physics, Leuven, Belgium; 2003. p. 363-7.

[8] Karagiozis AN. Advanced numerical models for hygrothermal research. Manual on moisture analysis in buildings; 2001. p. $90-103$. 
[9] Kunzel HM. Simultaneous heat and moisture transport in building components: one and two dimensional calculation using simple parameters. Ph.D. thesis, University of Stuttgart; 1994.

[10] EN 12524. Building materials and products-hygrothermal properties - tabulated design values.

[11] EN ISO 12572. Hygrothermal performance of building materials and products. Determination of water vapour transmission properties; 2001.

[12] EN ISO 12571. Hygrothermal performance of building materials and products. Determination of hygroscopic sorption properties; 2001.

[13] ISO 15148. Hygrothermal performance of building materials and products. Determination of water absorption coefficient by partial immersion.
[14] Freitas VP. Moisture transfer in building walls. Analysis of the interface phenomenon. Ph.D. thesis, FEUP, Porto; 1992 [in Portuguese].

[15] Freitas VP, Abrantes V, Crausse P. Moisture migration in building walls. Building and Environment-The International Journal of Building Science and it's Applications 1996;31(2):99-108.

\section{Further Reading}

[16] Colombert R. L'Humidité des bâtiments anciens; Causes et effets; Diagnostic et remèdes. Paris: Editions du Moniteur; 1975.

[17] Krus M. Moisture transport and storage coefficients of porous mineral building materials. Theoretical principles and new test methods. Fraunhofer IRB Verlag; 1996. p. 106. 